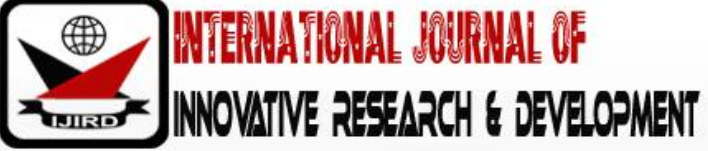

ISSN 2278 - 0211 (Online)

\section{Development of Mini Universal Testing Machine}

\author{
Ewtumo, T. \\ Reader, Department of Physics, Federal University of Technology, Akure, Nigeria \\ Popoola O.M., \\ Managing Director, E-Technogram Services, 11, Abu Alfred Street, Obawole, Lagos, Nigeria \\ Adeniyi 0 \\ Principal Technologist, Department of Science Laboratory, Federal Polytechnic, Nigeria \\ Giwa A.B \\ Ph.D. Student, Department of Physics, Federal University of Technology, Akure, Nigeria
}

\begin{abstract}
:
The research work was on development of universal testing machine to determine the stress-strain of materials of maximum tension capacity not exceeding $500 \mathrm{~N}$ and extension of $100 \mathrm{~mm}$ maximum. The developed machine consists of mechanical frame bevel gear drive with wiper dc motor, instrumentation and motor control. The mechanical structure is made of two steel fixed columns of $340 \mathrm{~mm}$ in length and $22.05 \mathrm{~mm}$ in diameter. The columns can with stand 3.5 Ton load. The fixed crosshead and moving crosshead they attached with lock clamp pointing to each other. A dc wiper motor was used to drive moving crosshead via bevel gear system arrangement attached with 230 mm fine thread bolt with pitch $0.02 \mathrm{~mm}$. The instrumentation is made of $100 \mathrm{~mm}$ active region long, $10 \mathrm{k} \Omega$, linear potentiometer with analog-todigital converter (ADS1115), load cell of $50 \mathrm{~kg}$, load cell amplifier with 24 bits serial output, keypad, micro SD card shield, liquid crystal display (LCD) and switches for performance various operation. The motor DC drive consists of wiper motor dc, dc motor H-bridge bidirectional drive. The machine has maximum extension of $100.000 \mathrm{~mm}$ with resolution of $0.002 \mathrm{~mm}$ and maximum applied force of 500.000 Nwith resolution of $0.001 \mathrm{~N}$. The instrument was tested and performance evaluation was carried out the result obtained shows that force measuring unit and extensometer has correlation of 0.985 and 0.997 respectively also mean deviation is $0.00241 \mathrm{~N}$ and $0.000213 \mathrm{~mm}$ compared with available standard weight and vainer calliper respectively.
\end{abstract}

Keywords: Stress, strain, load cell, linear potentiometer, gear system

\section{Introduction}

Mechanical testing plays an important role in evaluating fundamental properties of engineering materials as well as in developing new materials and in controlling the quality of materials for use in design and construction Hashemi (2006). It has been established that any given material has a number of interesting and useful mechanical properties, and that these properties are often interrelated, it follows that we need to be able to measure all of them. It would be nice if one type of test could measure all of them but, unfortunately, no one test can do this. The tensile test, however, which can be used to measure a number of the most commonly used mechanical properties, is a very good place to start Meir (2004) and Huang (2009).

Compression testing is a method for assessing the ability of a material to withstand compressive loads. This test is commonly used as a simple measure of workability of material in service. Materials behave differently in compression than they do in tension so it may be important to perform mechanical tests which simulate the condition the material will experience in actual use (Hassan and Bukar, 2009). Because of difficulties in obtaining accurate information from a compression test on ductile material, very little compression testing is done on metal (Bukar 1992). Difficulty arises from two causes, namely compression instability and frictional restraint. The compression test finds greatest use in testing brittle materials such as mortar, concrete brick and ceramic products, whose tensile strengths are low compared with their compressive strengths and which are principally employed to resist compressive forces (Stainslaw et.al., 2012 and Shi and Larkins, 1997).

Testing machines are used to develop better information on known materials or to develop new materials and maintain the quality of the materials. There are two classes of testing machines, electromechanical and hydraulic. A hydraulic testing machine uses either a single- or dual acting piston to move the crosshead up or down. In general, the electromechanical machine is capable of a wide range of test speeds and long crosshead displacements, whereas the hydraulic machine is a cost-effective solution for generating high forces and are manually operated. Materials education is a key foundation for engineering. But in this work as electromechanical stress-strain machine was developed using an Arduino microcontroller-based system with logging system. 


\section{Basic Block Diagram of The Mechanical Testing Machine and Mechanical Structure}

The block diagram in Figure 1 comprises two main units ,the first unit is the motor control which consists of dc motor, motor driver and pulse width generated from microcontroller.The second unit consists of two metric unit,namely the load tension or stress unit made of load cell, load cell amplifier with 24 bits serial out analog - to - digital converter (ADC) and Extensonmeter which comprises of 100mm long linear potentiometer and 16 bits ADC (ADS 1115). The second units are keypad to enter some fundamental parameters, SD card for data storage, LCD for display information of activities taken place in the system and microcontroller to co-ordinate all the activities together. The project can use battery or $12 \mathrm{~V}$, 5 Amp power pack.

Machanical structure shown in Figure 2 consist of Base and actuator unit.Internally, the the machine comprises of motor and iron gear systems with long fine thread screw that moves, the moving cross head speciment attachment on the top base and actuation , a table is place on it where two column made of spindle of steel of suck and of maza 323 car. The moving cross head is move to and fro slot

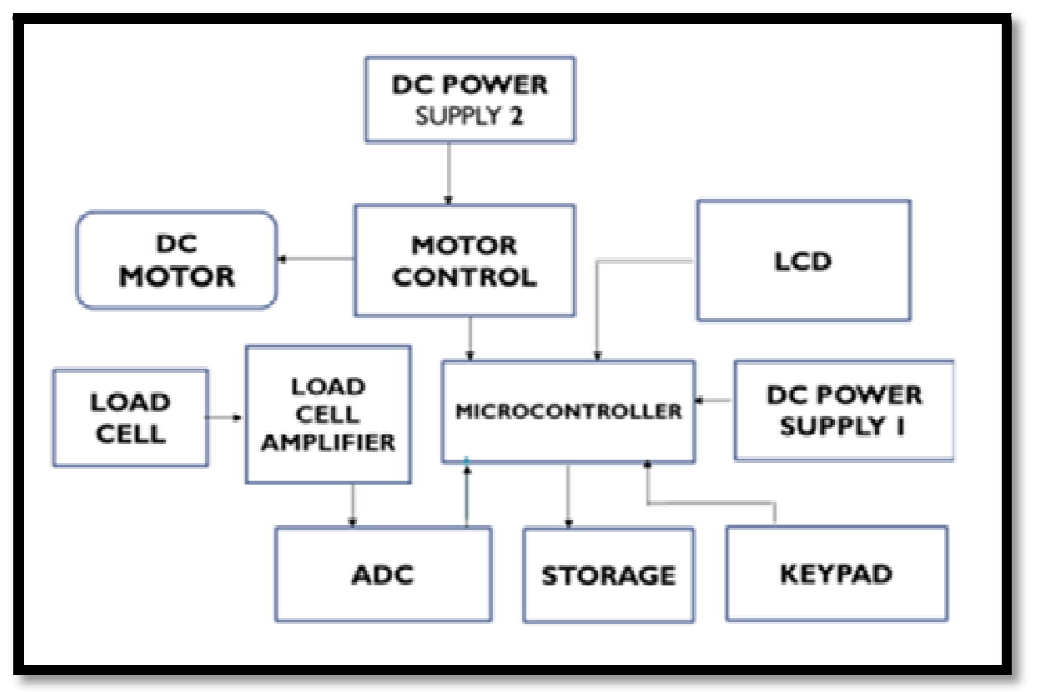

Figure 1: Basic Block Diagram of The

Mechanical Testing Machine

2.1. Machnical Structure of The Testing Machine

The mechanical structure consists of

- Two metal steel fixed column;

- Fixed and moving crosshead;

- Two lock clamps facing each other;

- Sold metal table; and

- Base and actuator.

The column has $340 \mathrm{~mm}$ length and $22.05 \mathrm{~mm}$ diameter with loading capacity of $3.65 \mathrm{ton}$. The steel column is obtained from the spindle of used Marza 323 suck and absorber. The fixed and moving crossheads were made of cast metal of $180 \mathrm{~mm} \times 80 \mathrm{~mm} \times 25 \mathrm{~mm}$. One of lock clamp was attached to a moving crosshead and second lock clamp attached to load cell when load cell is fixed to fixed crosshead as shown schematic diagram in Figure 2. A sold base of cast metal of $230 \mathrm{~mm} \times 180 \mathrm{~mm} \times 25 \mathrm{~mm}$. A fine thread bolt o $230 \mathrm{~mm}$ in length with pitch $0.02 \mathrm{~mm}$. The thread bolt was driving by a bevel gear power by a dc wiper motor arranged in the base and actuator housing with motor driving circuit, control circuit and metric circuit.

\subsection{Gear System}

In the speed reduction (before applied electronics speed control) and creation of high torque to applied force on materials under test. The two gearing systerm employed in the universal testing machine are worm gear and bevel gear that $230 \mathrm{~mm}$ bolt attached. The worm gear has high speed reduction and also has interesting property that on other gear set do not have: the worm can easily turn gear, but the gear cannot tur the worm, that is why is foud applicable in machine tools. The worm gear used has following data information when loaded speed is $28 \mathrm{rpm}$ with torque of $5.2 \mathrm{~N} . \mathrm{m}$ at $12 \mathrm{~V} / 5.6$ A. The bolt is attached to the bevel gear that been drived by worm gear system of wiper motor. The bevel is was used because it moved in both direction and with high torque capablity. 


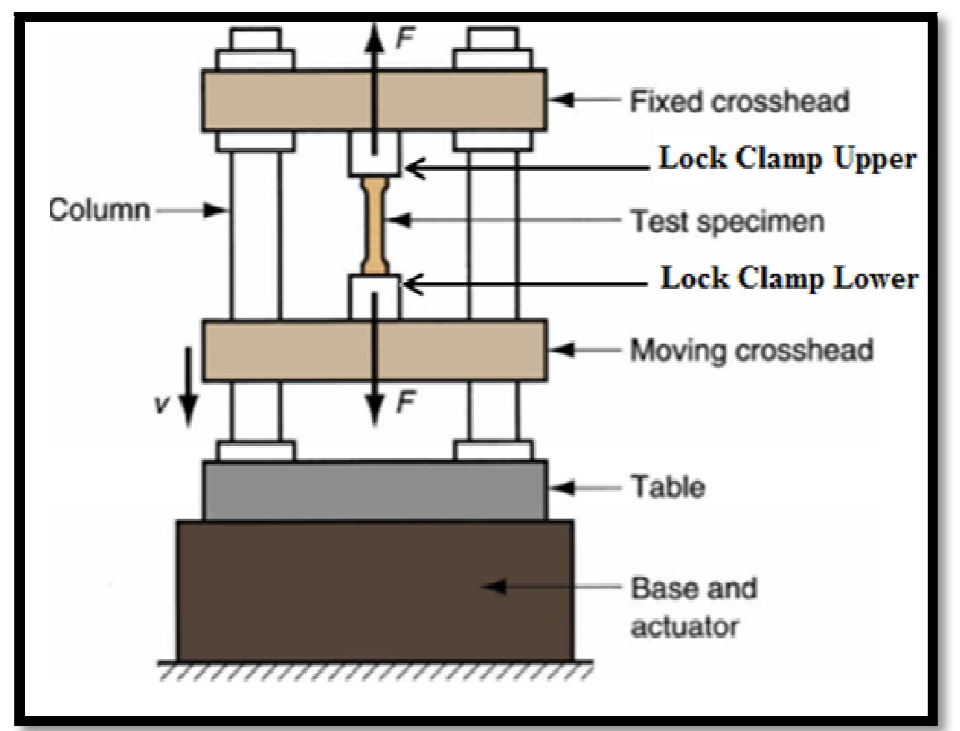

Figure 2: Mechanical Structure Concept and Design

\subsection{Load Cell Amplifier with 24 Bits Analog-to-Digital Conversion}

Based on Avia Semiconductor's patented technology, HX711 is a precision 24-bit analog-to-digital converter (ADC) designed for weigh scales and industrial control applications to interface directly with a bridge sensor. The input multiplexer selects either Channel A or B differential input to the low-noise programmable gain amplifier (PGA). Channel A can be programmed with a gain of 128 or 64 , corresponding to a full-scale differential input voltage of $\pm 20 \mathrm{mV}$ or $\pm 40 \mathrm{mV}$ respectively, when a 5V supply is connected to AVDD analog power supply pin. Channel B has a fixed gain of 32. On chip power supply regulator eliminates the need for an external supply regulator to provide analog power for the ADC and the sensor. Clock input is flexible. It can be from an external clock source, a crystal, or the on-chip oscillator that does not require any external component. On-chip power on-reset circuitry simplifies digital interface initialization. There is no programming needed for the internal registers. All controls to the HX711 are through the pins. The loads cell amplifier is link to microcontroller via DOUT of pin 12 HX711 to pin 3 on Arduino and PD SCK of pin 11 of HX711 to pin 2 of Arduino. The circuit diagram of HX711 is shown on Figure 3. (Ewetumo, 2019; Ewetumo et.al., 2019; Obagade and Ewetumo, 2019 and Theophilus et. al., 2019)

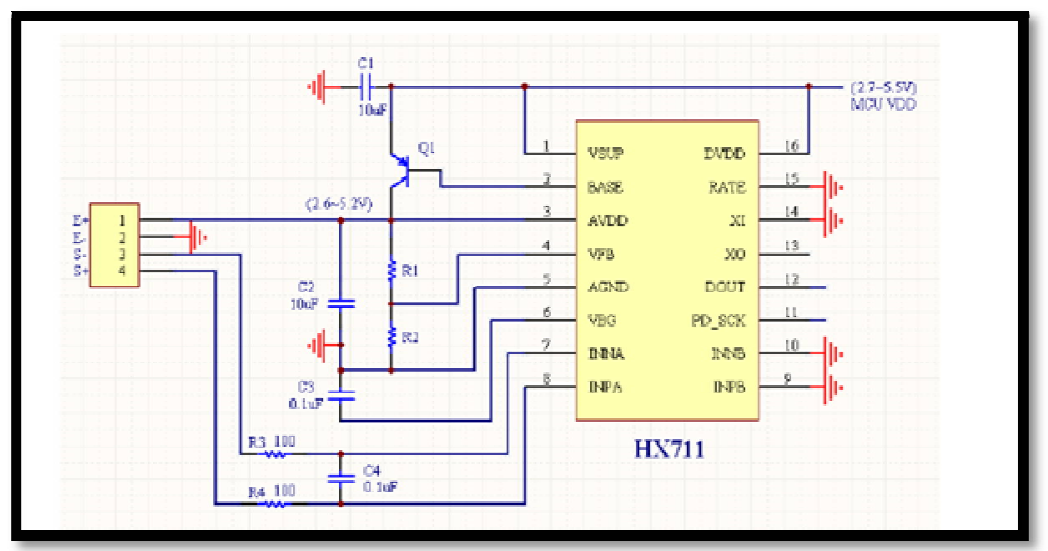

Figure 3: Circuit Diagram of Strain Gauge Amplifier (HX711)

\subsection{Extensometer with Analog-to-digital Converter (ADS1115)}

The Extensometer is a linear potentiometer (see Figure 4) with two ends of a straight resistor connected across the source voltage. A sliding contact can be slide on the resistor through a track attached along the resistor. The terminal connected to the sliding is connected one end of the output circuit and one of the terminals of the resistor is connected to the other end of the output circuit. To determine distance of elongation (strain) of sample material via extensometer,

$$
\begin{aligned}
& V_{\text {out }}=\frac{R_{1}}{R_{2}+R_{1}} \times V_{\text {ref }} \\
& L_{1} \propto V_{\text {out }} \cong L_{1}=q V_{\text {out }}
\end{aligned}
$$

where $\mathrm{q}$ in millimetre per volt $(\mathrm{mm} / \mathrm{V})$ is proportionality constant.

Substituting equation 1 in equation 2

$$
L_{1}=q \frac{R_{1}}{R_{1}+R_{2}} V_{\text {ref }}
$$


ADS1115 Full Scale and the value of bit are determined by the Programmable Gain Amplifier (PGA) setting as is this setting establishes full scale. This differs from the Arduino where full scale is determined by a reference voltage in the default mode, the setting is $+/-6.144$ volts. Thus, the value of 32767 would represent a value of 6.144 volts. Dividing 6.144 volts by 32767 yields a scale factor of $0.1875 \mathrm{mV}$ per bit. This is a significant improvement over the Arduino ADC which resolution of approximately $5 \mathrm{mV}$ per bit. In fact, it's about 26 times better. For better extensimeter reading another PGA setting, can be obtained as full scale of $H-2.048$ volts. That provides a resolution of $0.0635 \mathrm{mV}$. The Arduino microcontroller $r$ used an ADS library to the operation of ADS1115. To wire the ADS1115 to the microcontroller via SDA and SCL protocol. The output of the pot is link to A0 of ADS1115. The $\mathrm{V}_{\text {ref }}$ used is $2.048 \mathrm{~V}$. (Ewetumo et. al., 2019 and Osinowo et. al., 2019)

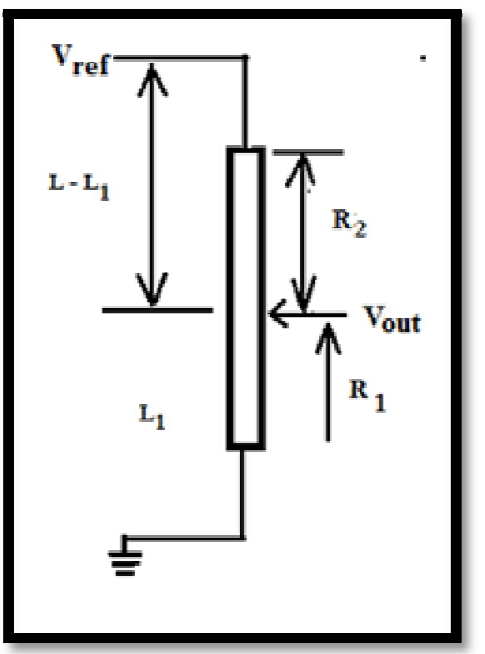

Figure 4: Pot Used as the

Extensometer

\subsection{Motor Driver}

The H- bridge motor driver is an electrical circuit that driving high current motor with very small current with the aid of cascade transistors arrangement. The H-bridge circuit driver used to control the wiper dc motor as shown in Figure 5. The motor can move in forward and reverse direction. An NPN transistors arrange in parallel $\left(\mathrm{Q}_{1}\right.$ and $\left.\mathrm{Q}_{3}\right)$ will be $\mathrm{ON}$ when logic HIGH (12V) applied to base of BD139 and transistors arrange in parallel $\left(\mathrm{Q}_{2}\right.$ and $\left.\mathrm{Q}_{4}\right)$ will be ON when logic LOW (0V) is applied to base of BD140. Table 1 shows the working mode of the H-bridge circuit. The $1 \mathrm{~N} 4007\left(\mathrm{D}_{1}-\mathrm{D}_{4}\right)$ were used as freewheeling diode so as to ensure fast switching of the circuit. These diode helps to avoid any problem from back emf of the dc motor. Resistors $\mathrm{R}_{1}-\mathrm{R}_{4}$ are used to limit the input current of the transistors, and the circuit was designed in such a way that the transistors work as a switch.

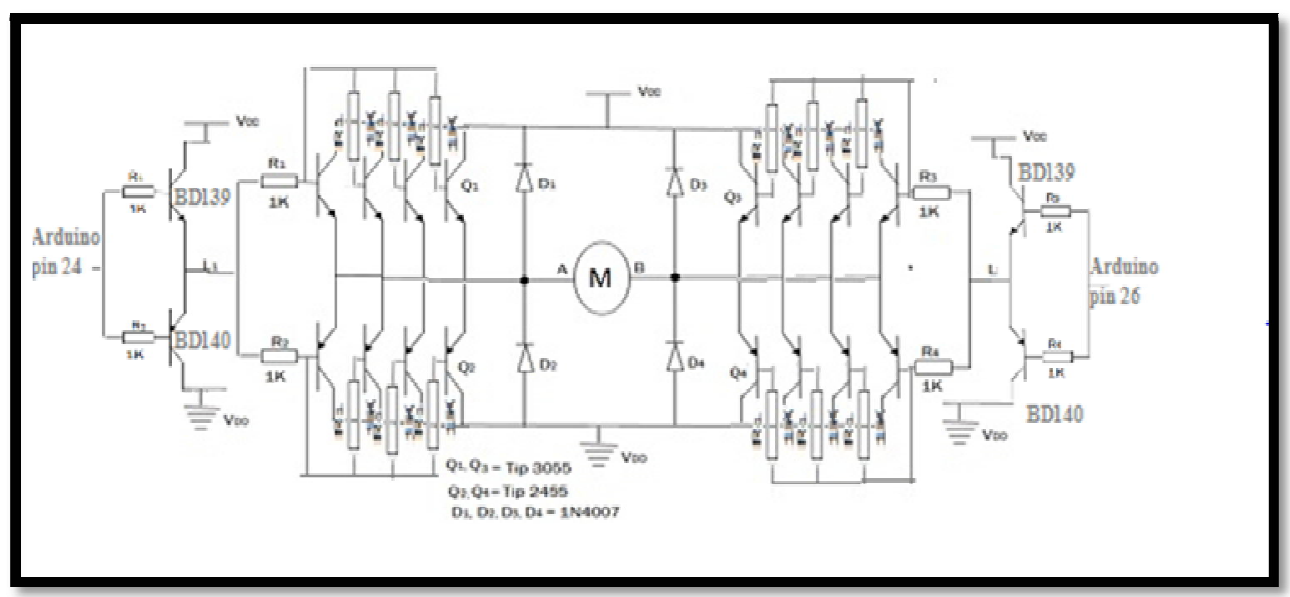

Figure 5: H-Bridge Motor Driver Circuit

\begin{tabular}{|c|c|c|c|c|}
\hline $\boldsymbol{L}_{\mathbf{1}}$ & $\boldsymbol{L}_{\mathbf{2}}$ & $\mathbf{A}$ & $\mathbf{B}$ & Action \\
\hline Logic 0 & Logic 0 & $0 \mathrm{~V}$ & $0 \mathrm{~V}$ & Stop \\
\hline Logic 1 & Logic 0 & $12 \mathrm{~V}$ & $0 \mathrm{~V}$ & Clockwise \\
\hline Logic 0 & Logic 1 & $0 \mathrm{~V}$ & $12 \mathrm{~V}$ & Anti-Clockwise \\
\hline Logic 1 & Logic 1 & $12 \mathrm{~V}$ & $12 \mathrm{~V}$ & Stop \\
\hline
\end{tabular}

Table 1: H-Bridge Driver Circuit Working Principle 


\subsection{Microcontroller Unit with Logging and Display Unit}

Microcontroller is small size computer on a single IC containing processor core, memory and programmable input-output peripheral. Microcontrollers are designed for the use of embedded applications, in contrast with microprocessor which are used for personal computers and other general purpose applications. Atmega2560 is a low power, high performance; CMOS 8-bit microcontroller based on the AVR enhanced RISC architecture. Atmega2560 provides 256 Kbytes with 8 Kbyte RAM of in-system self-programmable memory with read while write capability and 2 Kbyte EPROM. The microcontroller coordinates all the activities of the instrument from accepting data from load cell amplifier to the processing of data to the storing and displaying information. (Pratik et al., 2014; Ewetumo et. al., 2019 and Osinowo et. al., 2019)

MicroSD card shield module was interfaced with microcontroller using Serial Peripheral interface (SPI) protocol standard. The module is designed for dual voltage power supply. The interface module can be used with two logic level i.e. CMOS 3.3V or TTL 5V.

The Liquid Crystal Display (LCD) is used to display the draught force during tillage operation for visual information. A Dig chip make 20 character $\times 4$ lines JHD162A liquid crystal display was used in the instrument developed. The display is a 16 pin which works with maximum power supply of $5.0 \mathrm{~V}$ and the data can be sent in either 4 bit, 2 operations or 8-bit, 1 operation so that it can be interfaced to 8-bit Microcontroller. Here we used 4 bits, 2 operation system. (Pratik et al., 2014; Ewetumo, 2019; Ewetumo et. al., 2019; Obagade and Ewetumo, 2019)

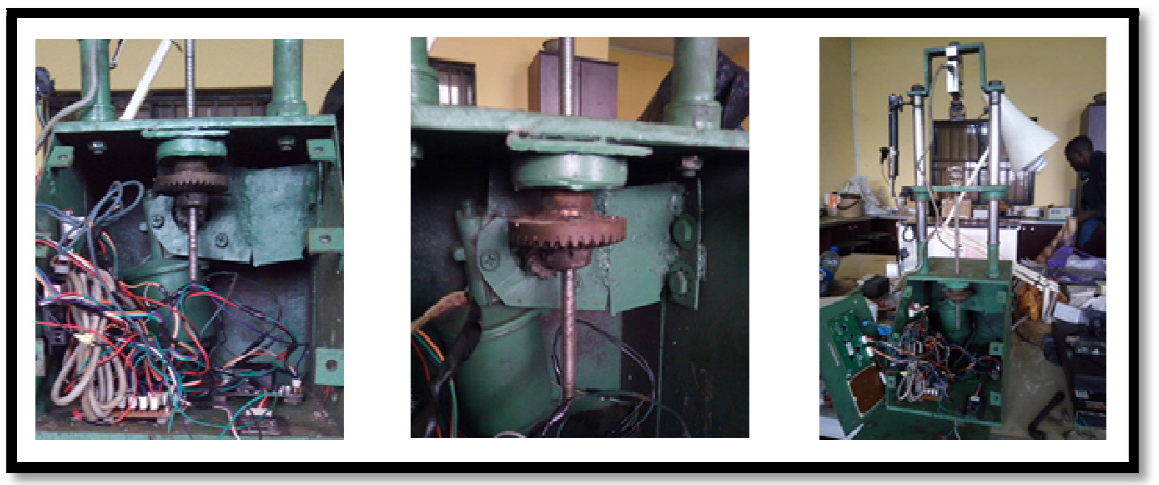

Figure 6: Developed Universal Testing Machine

\section{Testing, Calibration and Performance Examination}

\subsection{Load Cell Standardization}

The developed universal testing machine in Figure 6 consists of load cell and extensometer for calibration. The load cell was calibrated before used. The following steps were carried out for the calibration of the load cell in this project work they are:

- The load cell is connected to HX711 and Arduino;

- Sketch is uploaded and the serial monitor is used to monitor value and change calibration;

- Place a known weight on the load cell; and press 'a' or ' $z$ ' to adjust the calibration factor until the output readings match the known weight. 'a' is to increase the calibration factor whereas ' $z$ ' is to decrease the calibration factor.

After the standardization of load cell, few standard loads available in laboratory was to examine accuracy level of load cell measuring unit. Various value were place on load cell corresponding measurement were obtained as shown on Table 2 and Figure 6 explained linear relationship of the output. The correlation and mean deviation was obtained were 0.9987 and $0.0021 \mathrm{~kg}$ respectively.

\subsection{Verification of Extensometer}

A digital vainer callipers was used to verified the accuracy of the of extension measurement unit. The motor is set to move and stop at each instance the vainer calliper is used to measure corresponding distance moved. The value obtained is shown on Table 2. The result obtained were plotted linear expression and $\mathrm{R}^{2}$ value is 0.9872 , this explained for it accuracy reliable result. The mean deviation obtained was $0.000137 \mathrm{~mm}$.

\subsection{Operation of the Machine}

For the operation of the machine the following steps need to taken:

- When the machine is switch ON, the test specimen parameters such as thickness, breadth and length are entered via the $4 \times 4$ matrix keypad;

- Aftter enter specimen parameter and SWITCH label Mis release and the system enter WAITING mode;

- SWITCH F-R is press once and enter forward mode allow material to EXTEND;

- When SWITCH F-R press again it enter COMPRESSION mode;

- When SWITCH F-R is press third time enter WAIT mode; and

- When SWITCH P is press it returns MOVING CROSSHEAD upward.

- The memory card can be remove and copy store data for analysis. 


\begin{tabular}{|c|c|c|c|c|c|}
\hline \multicolumn{3}{|c|}{ Mass } & \multicolumn{3}{c|}{ Extension } \\
\hline Standard (g) & Measured(g) & deviation(g) & Measured (mm) & Caliper (mm) & deviation(mm) \\
\hline 100 & 100.042 & 0.042 & 1.024 & 1.02 & 0.004 \\
\hline 400 & 400.018 & 0.018 & 2.314 & 2.33 & 0.016 \\
\hline 500 & 499.976 & 0.024 & 4.506 & 4.51 & 0.004 \\
\hline 1000 & 1000.037 & 0.037 & 5.468 & 5.50 & 0.032 \\
\hline 1200 & 1200.084 & 0.084 & 8.112 & 8.09 & 0.022 \\
\hline 1400 & 1402.011 & 2.011 & 10.418 & 10.43 & 0.012 \\
\hline 1500 & 1501.256 & 1.256 & 14.456 & 14.43 & 0.026 \\
\hline 2000 & 2000.015 & 0.015 & 21.328 & 21.35 & 0.022 \\
\hline 2500 & 2501.002 & 1.002 & 25.338 & 25.35 & 0.012 \\
\hline 3000 & 3002.008 & 2.008 & 29.158 & 29.16 & 0.002 \\
\hline 3500 & 3501.217 & 1.217 & 34.018 & 34.07 & 0.052 \\
\hline 4000 & 3999.982 & 0.018 & 41.226 & 41.25 & 0.024 \\
\hline 4500 & 4502.001 & 2.001 & 48.112 & 48.09 & 0.022 \\
\hline 5000 & 5002.044 & 2.044 & 56.010 & 56.03 & 0.02 \\
\hline Correlation & 1.000 & & & & 1.000 \\
\hline mean deviation & & 0.841 & & & 0.019 \\
\hline
\end{tabular}

Table 2: Examination Load Cell and Extension Compared with Available Standard

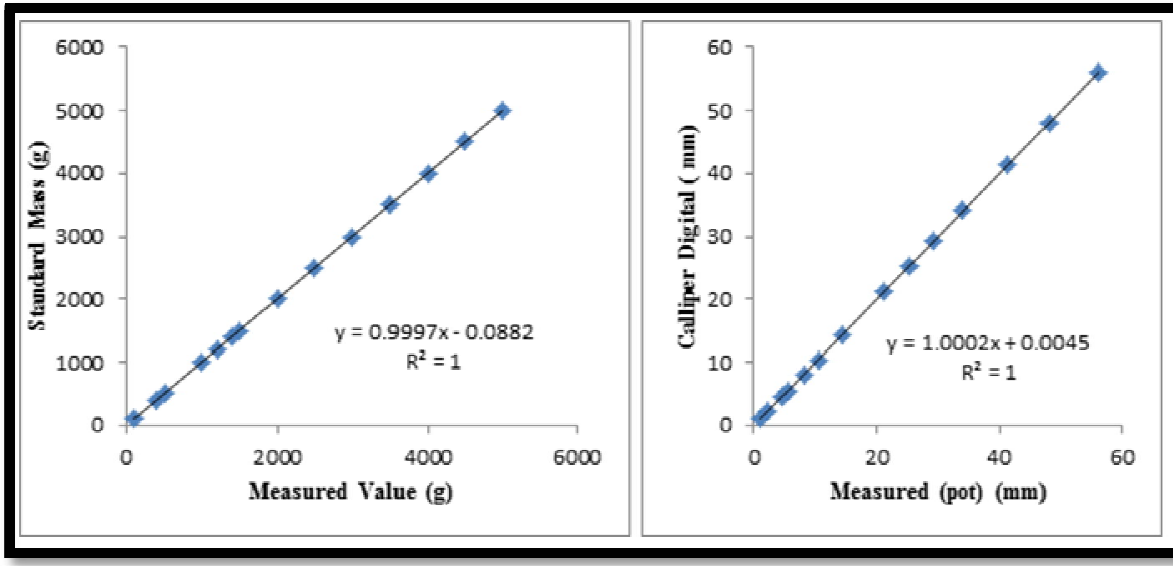

Figure 7: Standardization of Measuring Devices of Universal Testing Machine

\section{Conclusion}

In line with the objective which involve designed of motor controller and other metric unit. The controller can handle up to $25 \mathrm{Amp}$ dc motor to move both side directions. The extension can measure up to $100.000 \mathrm{~mm}$ at resolution of $0.0031 \mathrm{~mm}$. The tension measuring device up to $500.000 \mathrm{~N}$ with resolution of $0.001 \mathrm{~N}$. The developed mechanical frame for the mini universal testing device. It consists of bevel gear drive moving crosshead. The capacity of mini universal testing machine beyond $500.000 \mathrm{~N}$ by changing load cell up to $1 \mathrm{~T}$ and recalibrated.

\section{References}

i. Bukar Y. A. (1992). "Benefits of Enhanced Product Quality for Industries like Aluminium, Steel, Auto Mobile and related Industries" been paper presented at the seminar on Strategy for Developing Local Raw Materials for Metallurgical and Building Industries, Lagos.

ii. Hassan A.B. and Bukar Y. A., (2009). "Design and Fabrication of Compression Strength Testing Machine for Blocks and Clay Bricks", Leonardo Electronic Journal of Practices and Technologies. 14:142-153.

iii. Hashemi. A , (2006). Foundations of materials science and engineering, 4th ed, McGraw-Hill, ISBN 007-125690-3, 2006.

iv. Huang, Han-Way (2009): The HCS12/9S12: An Introduction to Software and Hardware Interfacing (Second Edition). Delmar Cengage Learning, New York.

v. Meier Mike, (2004). "Mechanical properties” Department of Chemical Engineering and Materials Science University of California, Davis.

vi. Shi J.D., and Larkins G. (1997). "A method of measuring the elastic modulus of thins" materials characterization, 38, (4-5): 301-303.

vii. Stanisław. A, B. Jerzy, and K. Czesław (2012). "Stress and strain measurements in static tensile tests". Metrology and Measurement systems, 19(3): 531-540.

viii. Ewetumo T. (2019): Development of a Low Cost Penetrometer with Depth Measurement, International Journal Scientific Research and Development (IJSRD), India. 7(4):483-486.

ix. Ewetumo T., Egbedele I., Joseph-Ojo. I., and Fagbamiye-Akinwale O. M. (2019): Development of Low-cost Soil Tillage Profilelometer, Iconic Research and Engineering Journal (IRE). India 3(2): 365-371. 
x. Theophilus Ewetumo, Kayode D Adedayo, Yusuf Lawal, Abiodun T Edun Joseph E Orokhe (2019): Development of an Automatic Body Mass Index Measurement Machine, FUOYE Journal of Engineering and Technology, Nigeria. 4(2):76-80.

xi. Obagade T. A., and Ewetumo T. (2019): Development of Microcontroller Base Draught Force, Iconic Research and Engineering Journal (IRE). India 3(2): 476-480.

xii. M. O. Osinowo, A. A. Willoughby, T. Ewetumoand L. B. Kolawole (2019): Development of Low-cost Soil Heat Flux and Temperature Profile with Logger, International Journal of Advance in Scientific Research and Engineering (ijasre) India. 5(7): 51-57.

xiii. Prarik, P, Rahul N., and Aunpsingh P. (2014): Design Solar Insolation Level Detector and Data Logger, International Journal of Current Engineering and Technology, 4(3), 2083-2087. 